\title{
ANALISIS VOLUME PENGERUKAN ALUR PELAYARAN BARAT SURABAYA DENGAN DATA MULTIBEAM ECHOSOUNDER MENGGUNAKAN PERANGKAT LUNAK HYPACK DAN AUTOCAD CIVIL 3D
}

\author{
Khomsin ${ }^{1}$, Irfan Maulana Yusuf ${ }^{2}$, Eko Yuli Handoko ${ }^{3}$ \\ Departemen Teknik Geomatika, FTSLK-ITS, Kampus ITS Sukolilo, Surabaya, 60111, Indonesia \\ e-mail: 2irvanmaulana2206@gmail.com
}

\begin{abstract}
Abstrak
Pelabuhan Tanjung Perak yang dilewati Alur Pelayaran Barat Surabaya (APBS) memiliki peran sebagai penggerak pertumbuhan perekonomian di bidang angkutan laut. Sungai-sungai yang bermuara ke APBS membawa sejumlah besar sedimen yang mengakibatkan pendangkalan, sehingga bisa mempengaruhi efektifitas APBS. Maka perlu dilakukan maintenance dredging perairan pelabuhan untuk mempertahankan kedalaman ideal. Pada penelitian ini akan melakukan perhitungan volume pengerukan dengan data dari survei multibeam echosounder di Alur Pelayaran Barat Surabaya menggunakan perangkat lunak Hypack dan AutoCAD Civil 3D dimana dari hasil tiap perangkat lunak akan dianalisa manakah perangkat lunak yang tepat untuk digunakan dalam pekerjaan pengerukan di laut. Metode perhitungan volume yang digunakan adalah penampang rata-rata dengan membagi perhitungannya per-section. Dari pengolahan data multibeam ini didapatkan hasil peta batimetri yang menunjukkan lokasi penelitian yang kurang dari 13 meter memiliki panjang alur 17,6 kilometer. Total nilai volume yang didapat dari perhitungan AutoCAD Civil 3D sebesar 5.921.745 $\mathrm{m}^{3}$, Hypack sebesar 5.952.881,83 $\mathrm{m}^{3}$, hitungan manual sebesar 5.326.096,17 $\mathrm{m}^{3}$, dan perhitungan menggunakan metode composite sebesar 5.881.819,17 $\mathrm{m}^{3}$. Hitungan RMSE pada AutoCAD Civil 3D terhadap hitungan manual dan metode composite adalah 354,78 dan 171,27, sedangkan nilai RMSE Hypack terhadap hitungan manual dan metode composite adalah 480,64 dan 264,76. AutoCAD Civil 3D adalah hitungan yang paling mendekati hasil hitungan manual dan metode composite sebagai pembanding.
\end{abstract}

Kata Kunci: Volume, Cross Section, Pengerukan

\begin{abstract}
The seaport Tanjung Perak passed through by western ship lane of Surabaya (APBS) has an important role as driving of economic growth in the field of sea transport. The rivers that flow to APBS has bringing large of sediments that caused of shallow on that area, so that influence the effectiveness of APBS. Hence maintenance dredging port water is needed to maintain the ideal depth. In this research will doing the calculation of dredging volume with data derives from multibeam echosounder survey in APBS using Hypack and AutoCAD Civil 3D software. The results of each software will be analysed to see which software will be used in doing dredging in the sea correctly. The volume calculation methode used is average end area divided by the result of calculation each section. From the multibeam data processing produces bathymetry map that indicates the study location with depth less than -13 meter with along cruise line 17.6 kilometers. Total value volume obtained from calculation AutoCAD Civil 3D amounting $5.921 .745 \mathrm{~m}^{3}$, Hypack amounting $5.952 .881,83 \mathrm{~m}^{3}$, manual calculation amounting 5.326.096,17 $\mathrm{m}^{3}$, and calculation using composite methode amounting $5.881 .819,17 \mathrm{~m}^{3}$. RMSE calculation on AutoCAD Civil 3D towards manual calculation and composite methode is 354.78 and 171.27 respectively, meanwhile Hypack RMSE value towards manual calculation and composite methode is 480.64 and 264.76. If compared to manual calculation and composite methode, AutoCAD Civil 3D is the most close count.
\end{abstract}

Keywords: Volume, Cross Section, Dredging 


\section{PENDAHULUAN}

Laut sebagai jalur komunikasi diartikan bahwa pemanfaatan laut untuk kepentingan lalu lintas pelayaran antar pulau, antar negara maupun antar benua baik untuk angkutan penumpang maupun barang, maka perlu ditentukan alur perlintasan laut kepulauan Indonesia bagi kepentingan pelayaran lokal maupun internasional serta fasilitas keselamatan pelayaran seperti Sarana Bantu Navigasi Pelayaran (SBNP), Telekomunikasi Pelayaran, dan Survey Hidrografi untuk menentukan alur pelayaran yang aman serta infrastruktur lainnya. Penentuan alur pelayaran ditinjau dari aspek keamanan bernavigasi dimaksudkan agar alur terhindar dari karang yang tenggelam sewaktu air surut (low elevation tide), dangkalan ataupun karang tumbuh, dan kedalaman dasar laut yang tidak aman untuk draft kapal.

Pelabuhan Tanjung Perak memiliki peran strategis guna menunjang kegiatan lalu lintas transportasi angkutan laut dan sebagai penggerak pertumbuhan perekonomian. Setiap tahun pertumbuhan arus barang baik domestik maupun internasional, mengalami peningkatan melebihi kapasitas yang ada. Demikian juga dari tahun ketahun nilai pasang surut dan sedimen dasar laut selalu berubah. Dermaga Jamrud Utara merupakan salah satu dermaga yang ada di Pelabuhan Tanjung Perak, dengan arus keluar masuk kapal yang cukup padat, karena merupakan dermaga internasional. Tercatat pada tahun 2011 ada 14.117 kapal berlabuh di Jamrud Utara, sedangkan pada tahun 2012 mengalami peningkatan menjadi 14.773 kapal, sumber data berasal dari data traffic kapal Pelabuhan Tanjung Perak. Semua kapal yang akan berlabuh di Pelabuhan Tanjung Perak harus melewati Alur Pelayaran Barat Surabaya.

Sungai-sungai yang bermuara ke APBS membawa sejumlah besar sedimen yang mngakibatkan pendangkalan, sehingga bisa mempengaruhi efektifitas APBS [3]. Untuk menyelesaikan permasalahan sedimentasi dan memelihara kualitas pelayanan, perlu diperhatikan kondisi alur pelayaran sebagai jalan masuk kapal ke wilayah pelabuhan dan arah kapal masuk ke perairan pelabuhan. Kedalaman alur pelayaran yang tidak sesuai dengan draft kapal dapat mengakibatkan kapal kandas dan membahayakan keselamatan pelayaran. Oleh karena itu, perlu dilakukan maintenance dredging perairan pelabuhan untuk mempertahankan kedalaman ideal yang sesuai dengan dimensi dan ukuran kapal.

Penelitian ini akan melakukan perhitungan volume pengerukan dengan data dari survei multibeam echosounder di Alur Pelayaran Barat Surabaya menggunakan perangkat lunak Hypack dan AutoCAD Civil 3D dimana dari hasil tiap perangkat lunak akan dianalisa manakah perangkat lunak yang tepat untuk digunakan dalam pekerjaan pengerukan di laut.

\section{METODE}

\section{Lokasi Penelitian}

Lokasi daerah penelitian berada di Alur Pelayaran Barat - Pelabuhan Tanjung Perak Surabaya, yang secara geografis terletak antara $6^{\circ} 50^{\prime} 00^{\prime \prime}$ LS $7^{\circ} 00^{\prime} 00^{\prime \prime}$ LS dan $112^{\circ} 40^{\prime} 00^{\prime \prime}$ BT - $112^{\circ} 45^{\prime} 00^{\prime \prime}$ BT.

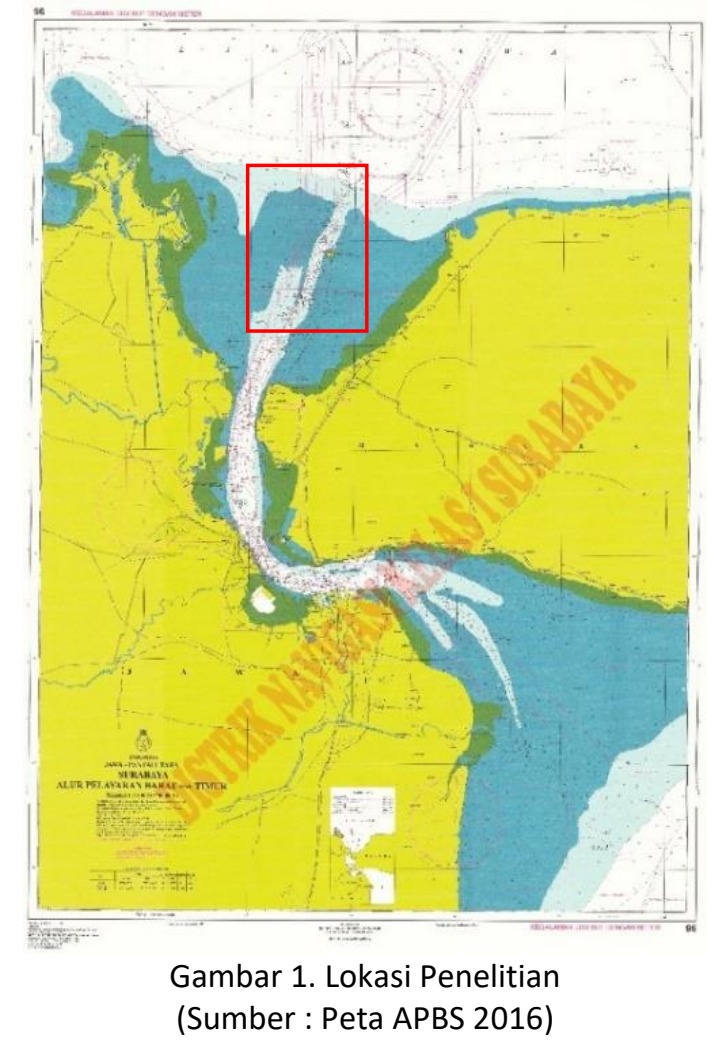

\section{Data dan Peralatan}

a. Data

Data yang dibutuhkan dalam penelitian ini diperoleh dari Distrik Navigasi (DisNav) yang terdiri dari:

1. Data ASCII multibeam echosounder Alur Pelayaran Barat Surabaya bulan Juni 2017 dari instansi Disnav. 
2. Peta Laut Indonesia Alur Pelayaran Barat Surabaya 2016 dari instansi Disnav.

b. Peralatan

Perangkat Lunak (Sofware) yang digunakan dalam pengerjaan penelitian ini antara lain:
i. AutoCAD Civil 3D
ii. Hypack
iii. ArcGIS 10.3

\section{Tahap Pengolahan Data}

Tahapan pengolahan data pada penelitian ini adalah sebagai berikut:

1. Data List

Tahap ini akan menentukan daerah yang akan dilakukan perhitungan volume pengerukan dengan ketentuan kedalaman kurang dari -13 meter.

2. Perhitungan Volume Manual

Perhitungan volume secara manual menggunakan metode penampang rata-rata. Hasil dari perhitungan volume secara manual akan dijadikan standar sebagai pembanding dari hasil perhitungan volume dari perangkat lunak AutoCAD Civil 3D dan Hypack.

3. Layouting

Data ASCll yang didapat akan dimasukkan kedalam perangkat lunak ArcGIS lalu dilakukan layouting untuk menghasilkan peta batimetri yang digunakan sebagai data primer pekerjaan pengerukan.

4. Plotting Data ASCII ( $x$ y z)

Setelah mendapatkan data ASCII $(x, y, z)$ data selanjutnya dilakukan plotting pada perangkat lunak Hypack dan Civil 3D dari hasil pengolahan data multibeam di perangkat lunak Hypack.

5. Pembuatan DTM surface

Dari data $x, y, z$ yang sudah diplotting akan dimodelkan secara 3 dimensi menggunakan prinsip-prinsip jaring-jaring TIN yang solid sehingga didapatkan Digital Terrain Model (DTM) surface. Surface ini yang akan digunakan sebagai acuan dalam perhitungan volume pengerukan.

6. Pembuatan Desain Keruk

Pembuatan desain keruk dilakukan di tiap perangkat lunak HYPACK dan Civil 3D dengan spesifikasi desain yang sama. Ukuran desain keruk memiliki kemiringan slope 1:5 pada tiap section dan memiliki kedalaman -13 meter sesuai peraturan Alur Pelayaran Barat
Surabaya.

7. Pembuatan Cross Section

Dalam pembuatan peta Batimetri yang akan digunakan sebagai acuan dalam pengerukan, profil melintang (cross section) dasar laut sangat diperlukan untuk mengetahui seberapa banyak material dasar laut yang masih perlu dikeruk. Dalam pembuatan cross section ini, dibuatlah garis yang melintang (cross) di area yang telah disounding sesuai acuan desain pengerukan dengan jumlah sesuai dengan kebutuhan dan interval jarak yang sama.

8. Perhitungan Volume

Dari desain keruk dan cross section yang sudah dibuat dilakukan perhitungan nilai volume tiap section lalu dijumlah. Pada perangkat lunak HYPACK dan AutoCAD Civil 3D perhitungan volume sama-sama menggunakan metode Average End Area. Lalu dihitung juga perhitungan volume secara manual untuk dijadikan standar atau acuan.

9. Analisa Volume

Pengerukan Data yang telah diolah kemudian dianalisis sedemikian rupa sehingga diperoleh suatu hasil berupa analisis perbandingan nilai volume yang didapat dari perangkat lunak HYPACK dan Civil 3D dengan hasil perhitungan manual untuk dijadikan pembanding. Dari analisa tersebut akan diambil sebuah rekomendasi penggunaan perangkat lunak yang tepat untuk pekerjaan pengerukan.

\section{HASIL DAN PEMBAHASAN}

\section{Perhitungan Volume AutoCAD Civil 3D}

Informasi pada tabel volume di AutoCAD Civil 3D menyajikan informasi nilai luas tiap section dan penambahan nilai volume ke tiap sectionnya. Dari perhitungan volume menggunakan AutoCAD Civil 3D didapatkan nilai volume terkecil sebesar 35,1 $\mathrm{m}^{3}$ yang terletak pada section $17+626,77$, nilai yang kecil tersebut dikarenakan kedalaman di section tersebut mendekati -13 meter maka surface eksisting yang berada diatas desain keruk sedikit dan nilai volume terbesar sebesar $34.808,02 \mathrm{~m}^{3}$ yang terletak pada section $12+150$, nilai yang besar tersebut dikarenakan kedalaman di section tersebut cukup dangkal maka surface eksisting yang berada diatas desain keruk cukup banyak harus di-cut. Dengan nilai luas terkecil 
sebesar $0,58 \mathrm{~m}^{2}$ yang terletak pada section $17+626,77$ dan nilai luas terbesar $607,18 \mathrm{~m}^{2}$ yang terletak $12+100$. Dengan terbuatnya 353 cross section pada perhitungan volume menggunakan AutoCAD Civil 3D dengan menambahkan nilai siltation rate $10 \%$ didapatkan nilai sebesar $5.921 .745 \mathrm{~m}^{3}$. Informasi tabel volume AutoCAD Civil 3D dapat dilihat pada Tabel 1.

Tabel 1. Volume $\left(\mathrm{m}^{3}\right)$ Pada AutoCAD Civil 3D

\begin{tabular}{|c|c|c|c|c|}
\hline \multicolumn{5}{|c|}{ Total Volume Table } \\
\hline Section & $\begin{array}{c}\text { Jarak } \\
(\mathrm{m})\end{array}$ & $\begin{array}{l}\text { Luas } \\
\left(\mathrm{m}^{2}\right)\end{array}$ & $\begin{array}{r}\text { Volume } \\
\left(\mathrm{m}^{3}\right)\end{array}$ & $\begin{array}{r}\text { Akumulasi } \\
\left(\mathrm{m}^{3}\right)\end{array}$ \\
\hline $0+000.00$ & & 261,755 & & \\
\hline & 50 & & $12.847,804$ & $12.847,804$ \\
\hline $0+050.00$ & & 252,157 & & \\
\hline & 50 & & $12.193,248$ & $25.041,052$ \\
\hline $0+100.00$ & & 235,573 & & \\
\hline & 50 & & $13.275,133$ & $38.316,185$ \\
\hline $0+150.00$ & & 295,432 & & \\
\hline & 50 & & $15.897,923$ & $54.214,108$ \\
\hline $0+200.00$ & & 340,484 & & \\
\hline & 50 & & $16.839,062$ & $71.053,171$ \\
\hline $0+250.00$ & & 333,078 & & \\
\hline & 50 & & $16.371,865$ & $87.425,036$ \\
\hline $0+300.00$ & & 321,797 & & \\
\hline & 50 & & $15.549,753$ & $102.974,789$ \\
\hline $0+350.00$ & & 300,194 & & \\
\hline & 50 & & $14.674,992$ & $117.649,781$ \\
\hline $0+400.00$ & & 286,806 & & \\
\hline & 50 & & $14.394,287$ & $132.044,067$ \\
\hline $0+450.00$ & & 288,965 & & \\
\hline & 50 & & $14.610,490$ & $146.654,557$ \\
\hline $0+500.00$ & & 295,454 & & \\
\hline & & : & & \\
\hline & & : & & \\
\hline $12+050.00$ & & 547,780 & & \\
\hline & 50 & & $28.873,860$ & $3.618 .719,050$ \\
\hline $12+100.00$ & & 607,175 & & \\
\hline & 50 & & $34.808,018$ & $3.653 .527,068$ \\
\hline $12+150.00$ & & 558,109 & & \\
\hline Section & $\begin{array}{c}\text { Jarak } \\
(\mathrm{m})\end{array}$ & $\begin{array}{r}\text { Luas } \\
\left(\mathrm{m}^{2}\right) \\
\end{array}$ & $\begin{array}{r}\text { Volume } \\
\left(\mathrm{m}^{3}\right)\end{array}$ & $\begin{array}{r}\text { Akumulas } \\
\left(\mathrm{m}^{3}\right)\end{array}$ \\
\hline & & : & & \\
\hline & & : & & \\
\hline $17+550.00$ & & 2,869 & & \\
\hline & 50 & & 122,603 & $5.383 .369,453$ \\
\hline $17+600.00$ & & 2,035 & & \\
\hline & 50 & & 35,101 & $5.383 .404,554$ \\
\hline $17+626.77$ & & 0,587 & & \\
\hline
\end{tabular}

\section{Perhitungan Volume Hypack}

Hasil pengolahan volume dapat di-export menjadi file di microsoft excel dengan menunjukkan hasil tiap sectionnya. Dari perhitungan volume menggunakan Hypack didapatkan nilai volume terkecil sebesar $127,23 \mathrm{~m}^{3}$ yang terletak pada section 17+600, nilai yang kecil tersebut dikarenakan kedalaman di section tersebut mendekati -13 meter maka surface eksisting yang berada diatas desain keruk sedikit dan nilai volume terbesar sebesar 32.002,69 $\mathrm{m}^{3}$ yang terletak pada section $12+150$, nilai yang besar tersebut dikarenakan kedalaman di section tersebut cukup dangkal maka surface eksisting yang berada diatas desain keruk cukup banyak harus di-cut. Dengan nilai luas terkeceil sebesar $2,04 \mathrm{~m}^{2}$ yang terletak pada section $17+600$ dan nilai luas terbesar 613,01 $\mathrm{m}^{2}$ yang terletak $12+100$. Hasil nilai luas dan volume dalam satuan meter. Berikut adalah hasil dari luas dan volume pada tiap sectionnya dapat dilihat pada Tabel 2 .

Tabel 2. Volume $\left(\mathrm{m}^{3}\right)$ Pada Hypack

\begin{tabular}{|c|c|c|c|c|}
\hline \multicolumn{5}{|c|}{ Tabel Total Volume } \\
\hline Section & $\begin{array}{c}\text { Jarak } \\
(\mathrm{m})\end{array}$ & Luas $\left(m^{2}\right)$ & Volume $\left(\mathrm{m}^{3}\right)$ & Akumulasi $\left(\mathrm{m}^{3}\right)$ \\
\hline \multirow[t]{2}{*}{$0+000$} & & 259,310 & & \\
\hline & 50 & & $12.970,583$ & $12.970,583$ \\
\hline \multirow[t]{2}{*}{$0+050$} & & 259,543 & & \\
\hline & 50 & & $12.538,156$ & $25.508,739$ \\
\hline \multirow[t]{2}{*}{$0+100$} & & 241,950 & & \\
\hline & 50 & & $13.370,951$ & $38.879,690$ \\
\hline \multirow[t]{2}{*}{$0+150$} & & 292,869 & & \\
\hline & 50 & & $15.788,329$ & $54.668,019$ \\
\hline \multirow[t]{2}{*}{$0+200$} & & 338,647 & & \\
\hline & 50 & & $16.714,682$ & $71.382,701$ \\
\hline \multirow[t]{2}{*}{$0+250$} & & 330,022 & & \\
\hline & 50 & & $16.489,507$ & $87.872,207$ \\
\hline \multirow[t]{2}{*}{$0+300$} & & 329,534 & & \\
\hline & 50 & & $15.997,825$ & $103.870,032$ \\
\hline $0+350$ & & 310,361 & & \\
\hline & $\begin{array}{c}\text { Jarak } \\
(\mathrm{m})\end{array}$ & Luas $\left(m^{2}\right)$ & Volume $\left(\mathrm{m}^{3}\right)$ & Akumulasi $\left(\mathrm{m}^{3}\right)$ \\
\hline & 50 & & $14.911,721$ & $118.781,754$ \\
\hline \multirow[t]{2}{*}{$0+400$} & & 286,068 & & \\
\hline & 50 & & $14.325,271$ & $133.107,025$ \\
\hline \multirow[t]{2}{*}{$0+450$} & & 287,029 & & \\
\hline & 50 & & $14.657,138$ & $147.764,162$ \\
\hline \multirow[t]{3}{*}{$0+500$} & & 299,241 & & \\
\hline & & : & & \\
\hline & & : & & \\
\hline \multirow[t]{2}{*}{$12+050$} & & 543,847 & & \\
\hline & 50 & & $28.916,829$ & $3.643 .540,957$ \\
\hline \multirow[t]{2}{*}{$12+100$} & & 613,013 & & \\
\hline & 50 & & $32.002,692$ & $3.675 .543,650$ \\
\hline \multirow[t]{3}{*}{$12+150$} & & 559,313 & & \\
\hline & & $:$ & & \\
\hline & & : & & \\
\hline \multirow[t]{2}{*}{$17+500$} & & 11,567 & & \\
\hline & 50 & & 375,021 & $5.411 .583,522$ \\
\hline \multirow[t]{2}{*}{$17+550$} & & 2,967 & & \\
\hline & 50 & & 127,228 & $5.411 .710,751$ \\
\hline $17+600$ & & 1,955 & & \\
\hline
\end{tabular}


Berikut adalah total nilai volume dari semua section dengan menambahkan nilai siltation rate $10 \%$ dapat dilihat pada Tabel 3 .

Tabel 3. Total Volume $\left(\mathrm{m}^{3}\right)$ Pada Hypack

\begin{tabular}{lr}
\hline Desain & \multicolumn{1}{c}{ Volume $\left(\mathrm{m}^{3}\right)$} \\
\hline Slope Kiri & $839.934,84$ \\
Channel Tengah & $4.525 .591,71$ \\
Slope Kanan & $46.184,21$ \\
\hline Total: & $5.952 .881,83$ \\
\hline
\end{tabular}

Perhitungan Volume Penampang Rata-rata

Perhitungan volume cross section di Alur Pelayaran Pelayaran Barat Surabaya secara manual menggunakan metode yang sama dengan yang digunakan di AutoCAD Civil 3D dan Hypack yaitu penampang rata-rata. Cara menghitung volume dengan penampang rata-rata dapat dilihat pada rumus seperti dibawah:

$$
V=\left(\frac{A 1+A 2}{2}\right) L
$$

Perhitungan luas penampang menggunakan rumus seperti di bawah.

$A=\frac{((x 1 \cdot y 2+x 2 \cdot y n+x n \cdot y 1)-(y 1 \cdot x 2+y 2 \cdot x n+y n \cdot x 1))}{2}$

Hasil dari luas dan volume pada tiap sectionnya dengan menghitung manual dapat dilihat pada Tabel 4.

Pada perhitungan volume penampang rata-rata secara manual nilai volume terkecil terdapat pada section 0+050 - 0+100 sebesar $11.749,77 \mathrm{~m}^{3}$, nilai yang kecil tersebut dikarenakan kedalaman di section tersebut mendekati -13 meter maka surface eksisting yang berada diatas desain keruk sedikit dan volume terbesar terdapat pada section $0+750-0+800$ sebesar $17.944,89 \mathrm{~m}^{3}$, nilai yang besar tersebut dikarenakan kedalaman di section tersebut cukup dangkal maka surface eksisting yang berada diatas desain keruk cukup banyak harus di-cut. Total dari 353 section perhitungan volume dengan perhitungan manual penampang rata-rata dan ditambah dengan nilai siltation rate $10 \%$ adalah $5.326 .096,17 \mathrm{~m}^{3}$.
Tabel 4. Volume $\left(\mathrm{m}^{3}\right)$ Pada Hitung Manual

\begin{tabular}{|c|c|c|c|}
\hline \multicolumn{4}{|c|}{ Tabel Total Volume } \\
\hline Section & $\begin{array}{c}\text { Jarak } \\
(\mathrm{m})\end{array}$ & $\begin{array}{l}\text { Luas } \\
\left(\mathrm{m}^{2}\right)\end{array}$ & $\begin{array}{r}\text { Volume } \\
\left(\mathrm{m}^{3}\right)\end{array}$ \\
\hline \multirow[t]{2}{*}{$0+00$} & & 258,884 & \\
\hline & 50 & & $12.413,564$ \\
\hline \multirow[t]{2}{*}{$0+50$} & & 237,658 & \\
\hline & 50 & & $11.749,774$ \\
\hline \multirow[t]{2}{*}{$0+100$} & & 232,333 & \\
\hline & 50 & & $12.842,001$ \\
\hline \multirow[t]{2}{*}{$0+150$} & & 281,347 & \\
\hline & 50 & & $15.150,931$ \\
\hline \multirow[t]{2}{*}{$0+200$} & & 324,690 & \\
\hline & 50 & & $16.049,561$ \\
\hline \multirow[t]{2}{*}{$0+250$} & & 317,293 & \\
\hline & 50 & & $15.712,594$ \\
\hline \multirow[t]{2}{*}{$0+300$} & & 311,211 & \\
\hline & 50 & & $15.433,530$ \\
\hline \multirow[t]{2}{*}{$0+350$} & & 306,130 & \\
\hline & 50 & & $14.456,286$ \\
\hline \multirow[t]{2}{*}{$0+400$} & & 272,121 & \\
\hline & 50 & & $13.746,556$ \\
\hline \multirow[t]{2}{*}{$0+450$} & & 277,741 & \\
\hline & 50 & & $14.137,235$ \\
\hline \multirow[t]{3}{*}{$0+500$} & & 287,749 & \\
\hline & $:$ & & \\
\hline & $:$ & & \\
\hline \multirow[t]{2}{*}{$12+150$} & & 725,954 & \\
\hline & 50 & & $29.804,626$ \\
\hline \multirow[t]{3}{*}{$12+200$} & & 466,231 & \\
\hline & $:$ & & \\
\hline & $:$ & & \\
\hline \multirow[t]{2}{*}{$17+550$} & & 2,062 & \\
\hline & 50 & & 85,967 \\
\hline $17+600$ & & 1,377 & \\
\hline
\end{tabular}

\section{RMSE (Root Mean Square Error)}

Pada penelitian ini dilakukan perhitungan RMSE (Root Mean Square Error) dari volume AutoCAD Civil 3D dan Hypack terhadap hitungan manual dan AutoCAD Civil 3D metode composite. Perhitungan RMSE menggunakan rumus sebagai berikut.

$$
R M S E=\sqrt{\frac{\sum_{i=1}^{n}(\gamma i-y i)^{2}}{n}}
$$

Keterangan:

$X i$ : Nilai sebenarnya pada periode ke-i

$Y i$ : Nilai prediksi pada periode ke-i

$n$ : Jumlah data

Tabel 5. RMSE Volume $\left(\mathrm{m}^{3}\right)$ terhadap Hitungan Manual

\begin{tabular}{lr}
\hline & RMSE Volume $\left(\mathrm{m}^{3}\right)$ \\
\hline AutoCAD Civil 3D & 354,78 \\
Hypack & 480,64 \\
\hline
\end{tabular}


Pada perhitungan RMSE (Root Mean Square Error) diatas dapat diambil kesimpulan bahwa perhitungan pada AutoCAD Civil 3D mempunyai akurasi yang lebih baik karena nilai RMSE terhadap hitung manual penampang rata-rata dan Civil 3D metode composite lebih kecil daripada Hypack dengan nilai 354,78 dan 171,27 sedangkan nilai RMSE Hypack terhadap hitung manual penampang rata-rata dan Civil 3D metode composite sebesar 480,64 dan 264,76.

\section{PENUTUP}

Kesimpulan yang dapat diambil dari penelitian ini adalah sebagai berikut:

a. Dalam membandingkan hasil perhitungan volume pengerukan Alur Pelayaran Barat Surabaya menggunakan perangkat lunak AutoCAD Civil 3D dan Hypack terhadap hitungan manual. Total nilai volume yang didapat dari perhitungan AutoCAD Civil 3D sebesar $5.921 .745 \mathrm{~m}^{3}$, Hypack sebesar $5.952 .881,83 \mathrm{~m}^{3}$, dan hitungan manual sebesar $5.326 .096,17 \mathrm{~m}^{3}$.

b. Perbandingan perhitungan dilakukan dengan mengetahui nilai RMSE, didapat hitungan RMSE pada AutoCAD Civil 3D terhadap hitungan manual adalah 354,78 , sedangkan nilai RMSE Hypack terhadap hitungan manual adalah 480,64.

c. AutoCAD Civil 3D adalah hitungan yang paling mendekati hasil hitungan manual sebagai pembanding.

Saran dari penelitian ini adalah perlu adanya studi lebih lanjut tentang penyusunan peta dasar kadaster laut dan jenis-jenis data yang dibutuhkan, serta diperlukan visualisasi yang lebih detail pada lebih dari satu sample agar diketahui potensi kelautan yang ada di Indonesia khususnya Pulau Maratua.

\section{DAFTAR PUSTAKA}

Parwata, Gede. 2011. "Peran Distrik Navigasi Dalam Keselamatan Pelayaran". Bali: Kementerian Perhubungan.

Buana, Putu Angga. 2014. "Studi Penentuan Draft dan Lebar Ideal Kapal Terhadap Alur Pelayaran". Tugas Akhir, Jurusan Teknik Geomatika ITS. Surabaya.
Wahyuni, N., Armono, H., D., dan Sujantoko. 2013. "Analisa Laju Volume Sedimentasi di Alur Pelayaran Barat Surabaya (APBS)". Jurusan Teknik kelautan ITS. Surabaya. Badan Pusat Statistik Situbondo. 2016. Situbondo dalam angka 2015. Situbondo ; BPS.

Purwohardjo, Umaryono U. 1989. "Pengukuran Topografi". Jurusan Teknik Geodesi FTSP ITB: Bandung. 